\title{
Conquering the Outdoors with On-site Mass Spectrometry
}

\author{
Lars Mächler ${ }^{a}$, Matthias S. Brennwald ${ }^{a}$, Lina Tyroller ${ }^{\mathrm{ab}}$, David M. Livingstone ${ }^{\mathrm{a}}$, and Rolf Kipfer ${ }^{\star a c}$
}

\begin{abstract}
In recent years, mass spectrometers with a membrane inlet separating gases from water for final analysis have been used successfully for the on-site quantification of dissolved gases in surface waters. In 'classical' membrane inlet mass spectrometers (MIMS), the membrane directly separates the water from the high-vacuum environment of the mass spectrometer. The gas equilibrium MIMS (GE-MIMS) that is described in this review, however, makes use of an intermediate pressure reduction stage after the membrane inlet. Hence, the gas concentrations after the membrane are at steady state, near solubility equilibrium with the water to be analyzed. This setup has several advantages over classical MIMS, which enable autonomous and continuous in-field operation. The GE-MIMS can be used to acquire noble gas concentration time series (NGTS). Noble gases are useful tracers for physical gas exchange and transport in groundwater and other aqueous systems. Hence NGTS enable the temporal dynamics of physical gas exchange and transport in groundwater and other aqueous systems to be investigated. To determine the $\mathrm{O}_{2}$ turnover that has occurred in groundwater since recharge, both the $\mathrm{O}_{2}$ concentration in situ and the total input of $\mathrm{O}_{2}$ to the groundwater since recharge is needed. Determination of the latter is only possible if the relevant physical exchange and transport mechanisms can be quantified. In particular, gas exchange between soil air and groundwater often significantly affects groundwater $\mathrm{O}_{2}$ concentrations. Determination of $\mathrm{O}_{2}$ turnover in groundwater therefore requires a combined analysis of $\mathrm{O}_{2}$ and noble gas concentrations.
\end{abstract}

Keywords: Environmental monitoring · Groundwater · Lakes · Membrane inlet mass spectrometry . Noble gases

\section{Introduction}

Mass spectrometers are widely used in many modern environmental laboratories. However, these complex instruments are difficult to operate outside laboratories because their performance depends strongly on the stability of ambient conditions (e.g. room temperature and humidity). These conditions can be controlled very well in the laboratory, but not at the field sites where environmental scientists carry out their work. In addition, most mass spectrometric systems are heavy, bulky, and often rely on the availability of laboratory infrastructure (e.g. electricity, cooling water, tanks containing standard gases).

\footnotetext{
${ }^{*}$ Correspondence: Prof. Dr. R. Kipferac Tel. +41587655530

E-mail: Rolf.Kipfer@eawag.ch

aDepartment of Water Resources and Drinking Water Eawag, Swiss Federal Institute of Aquatic Science and Technology

Überlandstrasse 133

Dübendorf

Institute of Biogeochemistry and Pollutant Dynamics ETH Zürich

Institute of Geochemistry and Petrology

ETH Zürich
}

Nevertheless, in recent years mass spectrometry has started to conquer the 'harsh' conditions encountered outdoors. ${ }^{[1]}$ Membrane inlet mass spectrometers (MIMS), for instance, have been used successfully for the on-site quantification of dissolved gases in surface waters ${ }^{[2-7]}$ and in groundwater.[8,9] While MIMS easily provide the sensitivity required to quantify the targeted gases, they usually lack the long-term robustness and stability that is required if they are to be used at field sites for longer than a few days. The main reason for this lack of stability is that the sensitivity of the MS and the gas permeability of the membrane inlet are both dependent on temperature. We recently developed a MIMS method that circumvents these problems. The system autonomously quantifies the concentrations of dissolved gases (e.g. $\mathrm{He}, \mathrm{Ar}, \mathrm{Kr}, \mathrm{N}_{2}, \mathrm{O}_{2}, \mathrm{CO}_{2}$, and $\mathrm{CH}_{4}$ ) in (ground) water. The instrument is equipped with a quadrupole mass spectrometer coupled to a membrane inlet with a pressure reduction device.

Quantifying concentrations of dissolved $\mathrm{O}$ in water has become very easy and reliable using optodes, ${ }^{[10]}$ which can be operated autonomously for several days. For $\mathrm{CO}_{2},{ }^{[11]}$ and to a lesser extent $\mathrm{CH}_{4},{ }^{[12]}$ similarly powerful techniques are available that allow dissolved gas concentrations to be monitored in the field. The concentrations of these gases (especially $\mathrm{O}_{2}$ ) are im- portant biological variables in groundwater ${ }^{[13-17]}$ that directly influence microbial activity. However, it is equally important to quantify the turnover rates of such biochemical processes. Turnover rates reflect microbial activity and are directly linked to the availability of organic matter and to water quality. ${ }^{[13-18]}$

Microbially mediated aerobic respiration, with $\mathrm{O}_{2}$ as a reactant and $\mathrm{CO}_{2}$ as a product, is a prominent typical example of such a process. In order to determine the $\mathrm{O}_{2}$ turnover in groundwater - i.e. the mass of $\mathrm{O}_{2}$ per unit mass of groundwater that has been consumed since recharge both the in situ concentration of $\mathrm{O}_{2}$ and the total input of $\mathrm{O}_{2}$ into the groundwater need to be quantified. $\mathrm{O}_{2}$ is supplied to the groundwater by advection along with the infiltrating water during recharge and by the dissolution of air bubbles entrapped in the groundwater during fluctuations of the groundwater table. The dissolution of air bubbles results in the formation of a gas surplus (excess air) relative to atmospheric solubility equilibrium. ${ }^{[18-27]}$

Any quantification of $\mathrm{O}_{2}$ turnover relies on the accurate quantification of these two sources of dissolved $\mathrm{O}_{2}$. However, as $\mathrm{O}_{2}$ is not conservative, the initial $\mathrm{O}_{2}$ concentration can only be reconstructed using chemically conservative tracers that are subject to the same physical gas transport and exchange mechanisms as $\mathrm{O}_{2} \cdot{ }^{[\text {[e.g. } 22]}$ 
Atmospheric noble gases ( $\mathrm{He}, \mathrm{Ne}, \mathrm{Ar}, \mathrm{Kr}$, $\mathrm{Xe})$ are biogeochemically unreactive and therefore make suitable tracers for quantifying gas transfer into groundwater.

In contrast to $\mathrm{O}_{2}$, the measurement of noble-gas concentrations in environmental water samples commonly requires the use of laboratory-based static mass-spectrometry systems. This approach is limited to the sequential analysis of individual water samples that were taken in special airtight containers. ${ }^{[28-34]}$ However, the concentrations of $\mathrm{O}_{2}$ and noble gases dissolved in groundwater may exhibit a high degree of variability, both spatially and temporally. ${ }^{[14,21,35-37]}$ For instance, groundwater in the vicinity of a losing river is most likely prone to the same dynamics as the stream water itself with respect to its chemical composition. ${ }^{[38]}$ The concentrations of dissolved gases in groundwater (particularly $\mathrm{O}_{2}$ ) can vary significantly on short time-scales (hours or less). [e.g. 39-41] The application of laboratory-based mass spectrometric methods for the comprehensive study of gas dynamics (including the dynamics of noble gases) in groundwaters would be very costly in terms of time, labor, and finances.

In this review article, we discuss the design and application of our recently developed MIMS system. Our new MIMS allows on-site quantification of the concentrations of dissolved gases $\left(\mathrm{O}_{2}, \mathrm{CO}_{2}\right.$, $\mathrm{CH}_{4}, \mathrm{He}, \mathrm{Ar}$, and $\mathrm{Kr}$ ) at a temporal resolution of a few minutes, allowing highly resolved noble-gas concentration time-series (NGTS) to be acquired. Our MIMS therefore, for the first time, provides a practical approach to obtaining gas concentration data that allow the robust quantification of the biogeochemical turnover of $\mathrm{O}_{2}$ and other gases in groundwater and other aquatic environments. ${ }^{[18,41]}$

\section{The 'Gas Equilibrium' MIMS System}

Commonly used MIMS systems (Fig. 1A) employ a membrane to separate the water (or other liquid sample matrix) from the high vacuum of the ion source. ${ }^{[3-9]}$ The membrane is permeable only to gases, blocking liquid water. The efficiency of gas transfer depends on the material of the membrane, the temperature of the water, the rate of flow of the water along the membrane, and the physico-chemical properties of the gas species (e.g. molecular size and polarity[42]). Quantification of the concentrations of dissolved gases therefore requires accurate calibration of the gas-specific rates of analyte transfer across the membrane, as well as precise and accurate control of the variables controlling the gas transfer. Calibration and control of the gas transfer at the membrane
A)

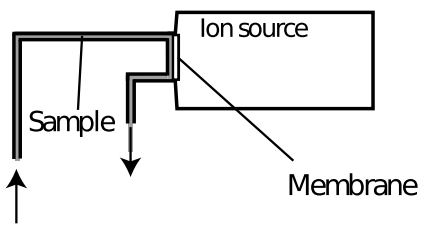

C)

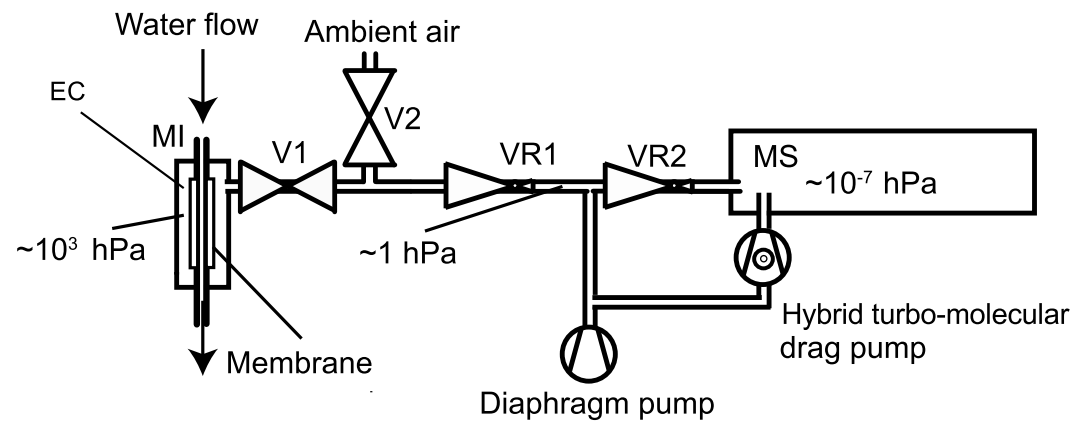

Legend

V1 \& V2: automated solenoid valves

VR1:

VR2:

MS:
B)

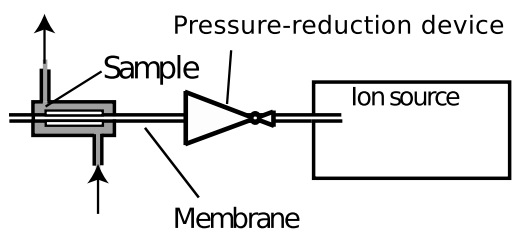

Fig. 1. Comparison of a 'classical' flow-through membrane inlet mass spectrometer (MIMS) with a gas equilibrium mass spectrometer (GE-MIMS). A) 'Classical' MIMS. ${ }^{[45]}$ B) GE-MIMS. C) GE-MIMS in more detail. ${ }^{[40]}$

inlet is technically challenging, precluding autonomous long-term use of this method in the field.

Other gas analysis systems - e.g. for dissolved $\mathrm{Rn}^{[43]}$ or $\mathrm{CO}_{2}^{[2]}$ - also rely on membrane separators. In these cases, however, equilibrium partitioning is established between the dissolved gases in the water and in a gas volume on the other side of the membrane. At steady state, it follows from Henry's Law that the partial pressure of a given gas in the gas volume depends only on the concentration of the gas in the water and on its (known) solubility. The partial pressures in the gas phase are determined using either an infrared gas analyzer ${ }^{[2]}$ or a radon sniffer, ${ }^{[43]}$ neither of which consumes any of the gas in the gas volume. For such systems, the specific properties of the membrane are only relevant during the process of attaining steady state and for the separation of the gases from the water, but do not affect the final partial pressures attained in the gas phase.

To overcome the inherent limitations of the classical MIMS system, we used a gasequilibrium approach in our GE-MIMS. [40] In this approach, the MS is coupled to a membrane module via a pressure-reduction device (Fig. 1B). In the membrane module, the gases equilibrate across a membrane that separates a gas volume (extraction chamber, EC) from the water, which is delivered by a water pump of the sort commonly used for groundwater sampling. A small fraction of the gas in the EC flows through the pressure-reduction device into the MS, where the targeted gas species are continuously analyzed.
In the GE-MIMS the pressure reduction is split into two stages (Fig. 1C). The first stage consists of a capillary tube (VR1) approximately $3 \mathrm{~m}$ long that reduces the pressure prevailing in the $\mathrm{EC}$ (e.g. near atmospheric pressure for air-saturated water) to a partial vacuum of approximately $1 \mathrm{hPa}$. This medium vacuum is maintained by a diaphragm pump, which extracts most of the gas. In the second stage the remaining gas is introduced through a metering valve (VR2) into the high vacuum of the MS $\left(<10^{-6} \mathrm{hPa}\right)$, which is maintained by a hybrid turbo-molecular drag pump. The gas flow from the EC into the capillary tube is kept low enough $\left(\sim 1 \mathrm{~mL}_{\mathrm{STP}} / \mathrm{min}\right)$ to avoid uncontrolled disturbance of the solubility equilibrium established in the membrane module, and a water pump is used to keep the water flow rate high enough ( $2 \mathrm{~L} / \mathrm{min}$ ) to replenish the gas transferred to the MS. Under these conditions, independent of the gas species, the partial pressures in the EC are reduced by $10 \%$ with respect to the partial pressures at solubility equilibrium (given by Henry's Law). The reduction in partial pressure remains constant over a large temperature range (4-36 $\left.{ }^{\circ} \mathrm{C}^{[40]}\right)$. Hence, the GE-MIMS circumvents the temperature dependence of the membrane's permeability to gases. The GE-MIMS requires a significantly higher water flow rate than a 'classical' MIMS (e.g. $\left.<10 \mathrm{~mL} / \mathrm{sample}^{[9]}\right)$. Such high flow rates, however, can normally be attained without difficulty when extracting water from aquifers or lakes.

The sensitivity of the MS in the GEMIMS is calibrated using ambient air, 
which is introduced via the capillary inlet (see Fig. 1 C, valves V1 and V2), because the partial pressures of $\mathrm{O}_{2}, \mathrm{~N}_{2}$, and the noble gases in the atmosphere are stable and known. ${ }^{[32]}$ Furthermore, the concentrations of atmospheric noble gases in groundwater and surface water are often similar to their respective concentrations in air-saturated water. The composition of noble gases in the EC is therefore often similar to that in the atmosphere. For the calibration of gases like $\mathrm{CH}_{4}$, a Teflar bag filled with a gas mixture containing the respective gas is connected to the capillary inlet. Regularly repeated calibration allows tight control of any drift in the sensitivity of the GE-MIMS that may occur with time.

The specific setup of the membrane module and the calibration procedure makes our GE-MIMS suitable for accurate and reliable long-term operation in the field. The entire system is constructed using off-the-shelf parts, which facilitates its construction and maintenance. The total cost of the equipment required to build the complete system (mass spectrometer, membrane module, pressure reducing system, pumps, etc.) is about CHF 40,000.

For example, the membrane inlet is a commercially available membrane module that is normally used to degas liquids. The valves for switching between air and the EC (V1 and V2) are automated solenoid valves, and the MS used in our GE-MIMS is a commercially available portable (35 $\mathrm{kg}$ ) residual gas analyzer (QMS 200, Stanford Research Systems, SRS). An aluminum box protects the MS and most of the associated electronic equipment from the weather (Fig. 2). For the sake of compactness and mobility, we mounted the system on a wheelbarrow. This allows the instrument to be transported to the field site in a van and, if necessary, to be pushed over rough terrain to the groundwater wells in the field by just one person. The entire system has a power consumption of around $300-600 \mathrm{~W}$ and therefore requires either a generator or a connection to a mains supply.

\section{Examples of GE-MIMS Applications in Field Studies}

\section{Using Noble Gases to Calculate the Input of Oxygen into Groundwater}

Noble-gas concentrations can be used to determine the formation of excess air and the related input of $\mathrm{O}_{2}$ to riparian groundwater.[e.g. ${ }^{21]}$ Here, we discuss an application of the GE-MIMS to study the $\mathrm{O}_{2}$ input that resulted from the formation of excess air in response to a flood event affecting a riparian groundwater system (the Thur aquifer, Niederneunforn, Switzerland). We performed a continuous analysis of

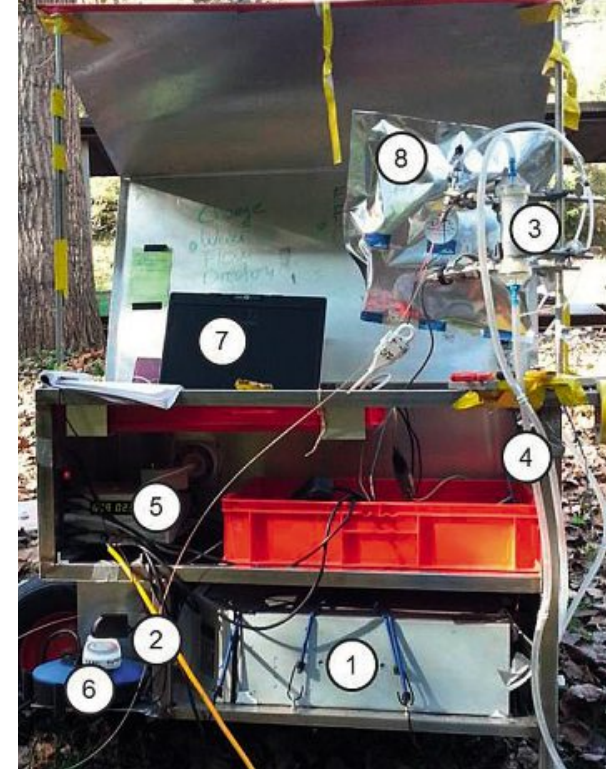

Fig. 2. The GE-MIMS in operation. 1) MS. 2) Pressure-reduction device with capillary tube. 3) Membrane module. 4) Water hoses connected to the water pump. 5) Power supply to the water pump. 6) Power supply to the MS. 7) Computer. 8) Teflar bag containing the calibration gas.

the concentrations of dissolved gases in several groundwater wells during a period of two weeks, during which a flood event occurred that induced an increase in groundwater level of almost $1 \mathrm{~m} .{ }^{[18]}$ Fig. 3 shows the response to the flood event of the He concentration in one of the groundwater wells. With the onset of the flood, the He concentration increased strongly, because the rise in the groundwater table resulted in the formation of excess air in the groundwater. After the flood receded, the He concentration decreased to pre-flood levels owing to the arrival of groundwater no longer affected by excess-air formation. Note that the young groundwater age (several days) means that concentrations of

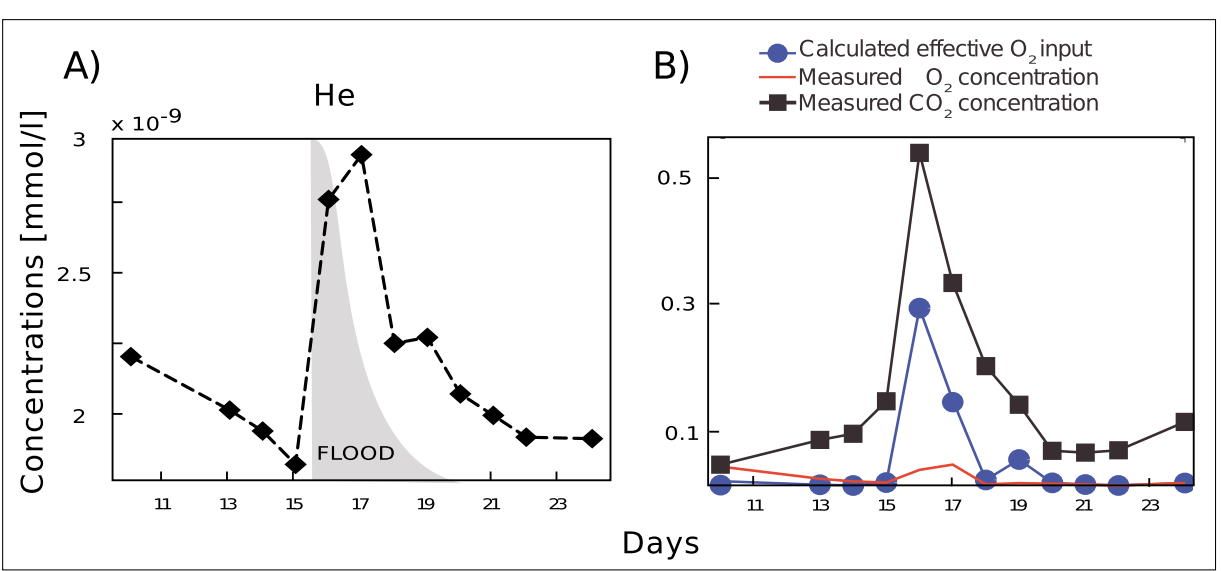

Fig. 3. Concentrations of gases measured in the groundwater of the Thur aquifer at Niederneunforn, Switzerland, from 10-24 May 2011, before, during and after the occurrence of a flood event in the River Thur (shaded area). A) Concentration of He, showing the increase during the flood event. B) Concentrations of $\mathrm{O}_{2}$ and $\mathrm{CO}_{2}$ input into groundwater as a result of the formation of excess air during the flood event. ${ }^{[12,18]}$ dissolved He are not affected by He fluxes originating from subterranean alpha decay.

The increase in the concentration of He resulting from the formation of excess air is normally more pronounced than the increase in the concentrations of the other noble gases. However, to correctly determine the parameters of the excess-air model, and hence to determine the input of $\mathrm{O}_{2}$ into the groundwater, the concentrations of $\mathrm{Ar}$ and $\mathrm{Kr}$ are also needed (for details on the excess-air model and the $\mathrm{Ar}$ and $\mathrm{Kr}$ concentrations, see ref. [18]). The $\mathrm{O}_{2}$ concentration calculated from the measured noble-gas concentrations (Fig. 3) indicates that the formation of excess air resulted in an input of $\mathrm{O}_{2}$ into the groundwater. However, the observed increase in the $\mathrm{O}_{2}$ concentration is much lower than the increase that is calculated to result from excess-air formation. While the observed $\mathrm{O}_{2}$ concentration remained relatively low during the flood, the $\mathrm{CO}_{2}$ concentration showed a substantial peak. Thus most of the $\mathrm{O}_{2}$ injected into the groundwater by the formation of excess air during the flood was immediately transformed by microbial respiration to $\mathrm{CO}_{2}$ before the water was analyzed for $\mathrm{O}_{2} \cdot{ }^{[18]}$

\section{Using NGTS to Determine Groundwater Residence Time for the Calculation of Oxygen Turnover}

Fig. 4 shows a time series of the concentration of Ar, determined using our GEMIMS, in the groundwater next to a losing river during low-flow conditions (Thur Niederneunforn $\left.{ }^{[41]}\right)$. The Ar concentration in the groundwater exhibited a diel cycle, with the minima occurring during nighttime and the maxima around noon. The amplitude and frequency of the diel cycle in the groundwater Ar concentration, and to a lesser extent also the curve shape, were similar to the amplitude, frequency and curve shape of the Ar concentration in the 
river given by the atmospheric solubility of Ar at the temperature of the river water. However, the groundwater Ar time series lags the river Ar time series by approximately 5-6 h (Fig. 4, see arrows). This similarity of the evolution of the Ar concentration in the river and in the groundwater indicates an advective groundwater flow from the river to the hyporheic zone of the aquifer with a groundwater travel time of 5-6 h. ${ }^{[41,44]}$

In analogy to Ar, the initial $\mathrm{O}_{2}$ concentration at groundwater recharge was also presumably set in the river, and so the $\mathrm{O}_{2}$ observed in the groundwater at the well had also traveled for 5-6 $\mathrm{h}$ from the river. The $\mathrm{O}_{2}$ turnover during the migration of the groundwater from the river to the observation well can therefore be calculated simply by subtracting the measured $\mathrm{O}_{2}$ concentration in the groundwater from the initial $\mathrm{O}_{2}$ concentration at recharge; i.e. the observed $\mathrm{O}_{2}$ concentration in the river around 5-6 $\mathrm{h}$ before the groundwater was sampled (for details see ref. [41]).

\section{Measuring Methane, Oxygen, and Carbon Dioxide Concentration Profiles in a Lake}

The GE-MIMS is also suitable for simultaneously measuring the concentration profiles of several dissolved gases in small lakes. In this case the instrument is

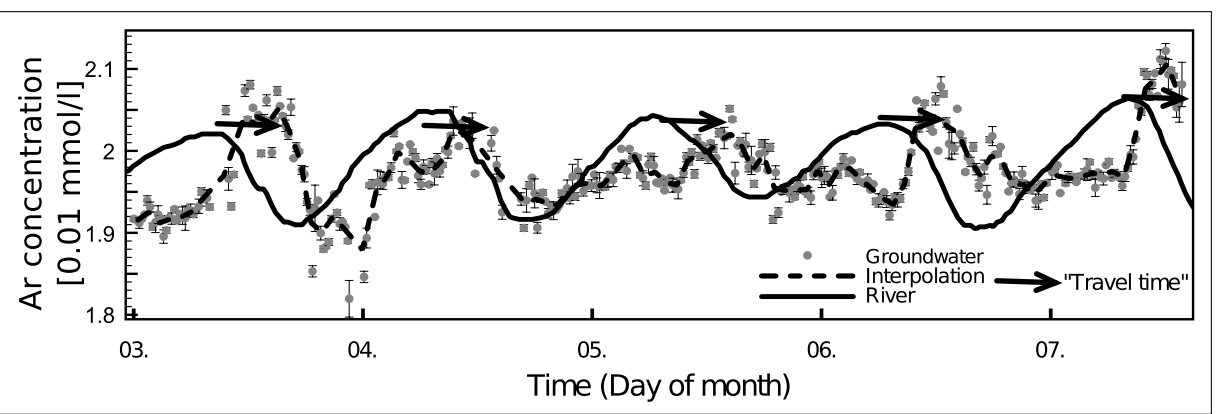

Fig. 4. Time series of the concentration of Ar measured in the groundwater of the Thur aquifer and in the River Thur at Niederneunforn, Switzerland, from 3-7 March 2011. The 'travel time' (5-6 h) is given by the lag between the groundwater and river water time series. ${ }^{[41]}$

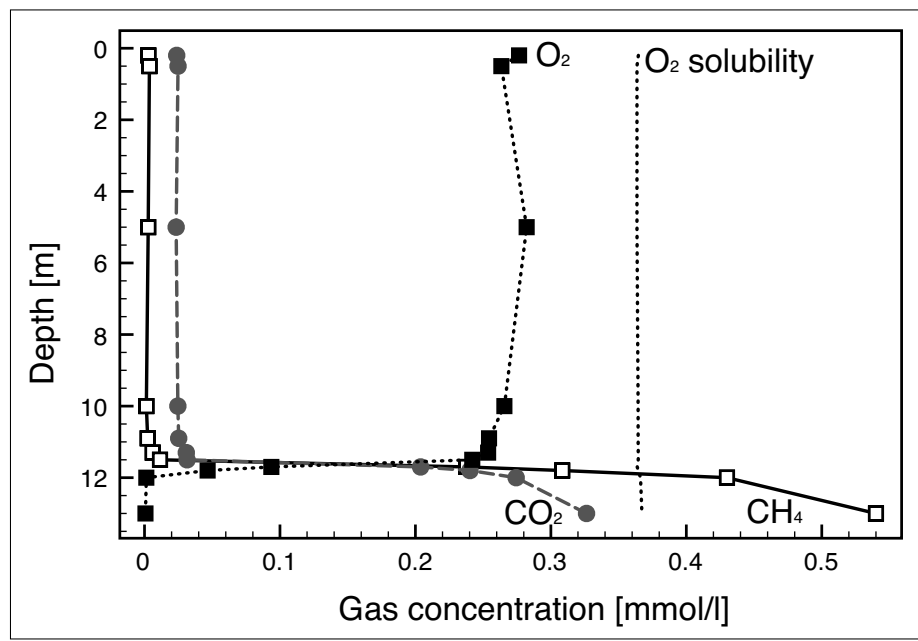

installed on a small boat and powered by a generator. The procedure is the same as for groundwater measurements; i.e. the submersible water pump is lowered to the desired depth to deliver the water to the membrane module.

Fig. 5 shows concentration profiles of $\mathrm{CH}_{4}, \mathrm{O}_{2}$, and $\mathrm{CO}_{2}$ acquired by the GEMIMS in Rotsee, a lake in the Canton of Lucerne, Switzerland, on November 30, 2010. On this date the lake, which has a maximum depth of $16 \mathrm{~m}$, was mixed down to $11.5 \mathrm{~m}$ and stratified below this depth. This is reflected in the abundance of $\mathrm{O}_{2}$ and the relatively low $\mathrm{CO}_{2}$ concentration down to $11.5 \mathrm{~m}$, despite photosynthesis taking place only in the upper few meters. Below the chemocline (i.e. the location in the water column of the strongest vertical gradient in the concentrations of dissolved compounds) at $11.5 \mathrm{~m}$ depth, owing to methane oxidation and aerobic respiration, the $\mathrm{O}_{2}$ concentration decreased rapidly to zero, coinciding with an increase in the $\mathrm{CO}_{2}$ concentration. Further, methane oxidation led to the rapid disappearance of $\mathrm{CH}_{4}$ above the chemocline. Below the chemocline, as a result of the continuous anaerobic production of $\mathrm{CO}_{2}$ and $\mathrm{CH}_{4}$ in the sediment and the stratification of the water column, $\mathrm{CH}_{4}$ and $\mathrm{CO}_{2}$ concentrations increased rapidly with depth. ${ }^{[44]}$ $\mathrm{CO}_{2}$, and $\mathrm{CH}_{4}$ concentrations in Rotsee, a lake in Switzerland, measured on 30 November 2010 using the GE-MIMS.

\section{Conclusions and Outlook}

The GE-MIMS represents, in principle, a simple modification to the conventional membrane-inlet concept that, for the first time, allows (quasi-)continuous time series of the concentrations of dissolved noble gases (NGTS) in groundwater to be measured autonomously and reliably. Simultaneously, the instrument can also measure the concentration of $\mathrm{O}_{2}, \mathrm{CO}_{2}$, and $\mathrm{CH}_{4}$. The GE-MIMS is suitable for on-site operation in environmental field campaigns, as fluctuations in the sensitivity of the system are controlled by regular calibration using either ambient air or a gas mixture at atmospheric pressure supplied in a Teflar bag as a gas standard. This calibration method is unique to membrane-inlet systems that work similarly to the GE-MIMS system. It is not feasible in the case of 'classical' MIMS systems, in which the extraction of gases from the water is affected by the poorly controlled gas transfer dynamics of the membrane inlet, and in which the analyte gases are transferred directly into the high vacuum of the MS. Compared to 'classical' MIMS systems, the GE-MIMS system has a longer response time and requires higher water flow rates $(2 \mathrm{~L} / \mathrm{min})$. However, the temporal resolution of four measurements per hour achieved for all analyzed gases suffices for the study of $\mathrm{O}_{2}$ dynamics in groundwater. ${ }^{[40,41]}$

The GE-MIMS is constructed to optimize its practical use in the field. The system is ruggedly constructed and requires no custom-made parts, which greatly simplifies repair and maintenance. In addition, the GE-MIMS can be installed in a compact wheelbarrow that allows straightforward transportation at field sites. The GE-MIMS is even suitable for operation at remote sites or on small boats, but in such cases electricity needs to be supplied by a generator.

Mass spectrometry in the field saves costs. In contrast to laboratory-based methods, which normally require several hours per measurement, the GE-MIMS requires about 15 minutes. Furthermore, knowledge of the concentrations of dissolved gases acquired during the field campaign enables further sampling to be better planned and hence saves time. Laboratory instruments are often expensive in terms of purchase price, construction, maintenance, and data acquisition based on large numbers of samples.

The GE-MIMS has allowed us to study the gas dynamics of aquatic systems in the environment. In particular, the acquisition of NGTS allows the formation of excess air in groundwater to be investigated. Furthermore, NGTS contain information on the temporal evolution of water tem- 
perature during the last occurrence of gas/ water partitioning, which can be used to determine the geochemical origin and the residence time of the groundwater being studied. ${ }^{411]}$

\section{Acknowledgments}

Part of this work was performed within the framework of the RECORD project (Assessment and Modeling of Coupled Ecological and Hydrological Dynamics in the Restored Corridor of a River (Restored Corridor Dynamics)), and was funded by Eawag (Swiss Federal Institute of Aquatic Science and Technology) and CCES (Competence Center Environment and Sustainability of the ETH Domain).

Received: February 8, 2014

[1] S. Taylor, V. M. Bierbaum, Int. J. Mass Spectrom. 2010, 295, 103.

[2] R. Carignan, Limnol. Oceanogr. 1998, 43, 969.

[3] P. Tortell, Limnol. Oceanogr-Meth. 2005, 324.

[4] M. Schlüter, T. Gentz, J. Am. Soc. Mass. Spectrom. 2008, 19, 1395.

[5] C. Gueguen, P. D. Tortell, Mar. Chem. 2008 108, 184.

[6] R. Camilli, A. Duryea, Environ. Sci. Technol. 2009, 43, 5014.

[7] J. M. Etzkorn, N. G. Davey, A. J. Thompson, A. S. Creba, C. W. LeBlanc, C. D. Simpson, E. T. Krogh, C. G. Gill, J. Chromatogr. Sci. 2009, 47, 57.

[8] W. Eschenbach, R. Well, Rapid. Commun. Mass. Spectrom. 2011, 25, 1993.

[9] A. Visser, M. J. Singleton, D. J. Hillegonds, C. A. Velsko, J. E. Moran, B. K. Esser, Rapid Commun. Mass Spectrom. 2013, 27, 2472.
[10] C. S. Chu, Y. L. Lo, T. W. Sung, Photonic. Sens. 2011, 1, 234.

[11] X. D. Wang, S. Wolfbeis, Anal. Chem. 2013, 85, 487.

[12] C. Boulart, M. C. Mowlem, D. P. Connelly, J. P. Dutasta, C. R. German, Opt. Express 2008, 16, 12607.

[13] H. Streeter, E. B. Phelps, Publ. Health Bull. 1925, 146

[14] R. Whitman, W. Clark, Hydrobiologia 1982, 92651.

[15] S. Korom, Water Resour. Res. 1992, 28, 1657.

[16] F. Malard, F. Hervant, Freshwater Biol. 1999, $41,1$.

[17] M. Rivett, S. Buss, P. Morgan, J. Smith, C. Bemment, Water Res. 2008, 42, 4215.

[18] L. Mächler, S. Peter, B. S. Matthias, R. Kipfer, Water Resour. Res. 2013, 49, 6847.

[19] T. H. E. Heaton, J. C. Vogel, J. Hydrol. 1981, 50201.

[20] M. Stute, P. Schlosser, J. F. Clark, W. S. Broecker, Science 1992, 256, 1000.

[21] U. Beyerle, W. Aeschbach-Hertig, M. Hofer, D. M. Imboden, H. Baur, R. Kipfer, J. Hydrol. 1999, 220, 169.

[22] R. Kipfer, W. Aeschbach-Hertig, F. Peeters, M. Stute, Rev. Mineral. Geochem. 2002, 47, 615.

[23] J. Holocher, F. Peeters, W. Aeschbach-Hertig, W. Kinzelbach, R. Kipfer, Environ. Sci. Technol. 2003, 37, 1337.

[24] J. Lippmann, M. Stute, T. Torgersen, D. Moser, J. Hall, L.-H. Lihung, M. Borcsik, R. E. S. Bellamy, T. C. Onstott, Geochim. Cosmochim. Acta 2003, 67, 4597.

[25] S. Klump, Y. Tomonaga, P. Kienzler, W. Kinzelbach, T. Baumann, D. Imboden, R. Kipfer, Geochim. Cosmochim. Acta 2007, 71, 1385.

[26] T. Sun, C. M. Hall, M. C. Castro, K. C. Lohmann, P. Goblet, Geophys. Res. Lett. 2008 35, L19401.
[27] W. Aeschbach-Hertig, D. K. Solomon, $A d v$. Isot. Geochem. 2013, 81 .

[28] R. F. Weiss, Deep-Sea Res. 1968, 15695.

[29] W. C. Poole, K. W. Stewart, Hydrobiol. 1976, $50,151$.

[30] U. Beyerle, W. Aeschbach-Hertig, D. Imboden, H. Baur, T. Graf, R. Kipfer, Environ. Sci. Technol. 2000, 34, 2042.

[31] J. T. Kulongoski, D. R. Hilton, Geochem. Geophys. Geosyst. 2002, 3, 1 .

[32] M. S. Brennwald, M. Hofer, R. Kipfer, Environ. Sci. Technol. 2013, 47, 8599.

[33] R. Wieler, Ref. Mod. Earth Sys. Env. Sci. 2014, 15355.

[34] J. Sültenfuß, W. Roethera, M. Rheina, 2009, 45, 83.

[35] M. Williams, M. Oostrom, J. Hydrol. 2000, 230, 70.

[36] R. G. S. Ingram, K. M. Hiscock, P. F. Dennis, Environ. Sci. Technol. 2007, 41, 1949.

[37] G. Massmann, J. Sueltenfuss, J. Hydrol. 2008, 359, 235.

[38] J. Kirchner, X. Feng, C. Neal, Nature 2000 , 403, 524.

[39] M. Hayashi, T. Vogt, L. Mächler, M. Schirmer, J. Hydrol 2012, 450-45193-104.

[40] L. Mächler, M. Brennwald, R. Kipfer, Environ. Sci. Technol. 2012, 46, 8288 .

[41] L. Mächler, M. S. Brennwald, R. Kipfer, Environ. Sci. Technol. 2013, 47, 7060.

[42] T. Kotiaho, F. Lauritsen, Compr. Anal. Chem. 2002, 16531

[43] A. Schmidt, M. Schlueter, M. Melles, M. Schubert, Appl. Radiat. Isotopes 2008, 66, 1939.

[44] C. J. Schubert, F. S. Lucas, E. Durisch-Kaiser, R. Stierli, T. D. ller, O. Scheidegger, F. Vaquez, B. Müller, Aquat. Sci. 2010, 72455.

[45] T. Kotiaho, J. Mass Spectrom. 1998, 31, 1. 